\title{
Utilization of esterified sago bark fibre waste for removal of oil from palm oil mill effluent
}

\begin{abstract}
With oil and grease content of $4000-8000 \mathrm{mg} / \mathrm{l}$ in palm oil mill effluent (POME), the commonly used ponding system often fails to produce treated effluent that meets the minimum standard of treated effluent. The present study investigates the efficiency of sago bark (SB) and esterified sago bark (ESB) for removal of emulsified oil from POME. Oil removal experiments were conducted at different batch experimental conditions: namely adsorbent dosage, contact time, temperature and $\mathrm{pH}$. In overall, the oil removal efficiency of both SB and ESB increased with the increasing of sorbent dosage and contact time. 24-h oil adsorption test afforded oil removal efficiency of $57.77 \%$ (SB) and $80.23 \%$ (ESB).On the other hand, the oil removal efficiency of both SB and ESB decreased with the increasing temperature. Acidic $\mathrm{pH}$ was favorable $\mathrm{pH}$ condition for high oil removal efficiency in POME. There was a good correlation $(\mathrm{R} 2>9.5)$ between experimental data and the intra-particle diffusion model for both SB and ESB. The adsorption of oil in POME using SB was best described by Freundlich isotherm $(\mathrm{R} 2=0.998)$, indicating heterolayer adsorption of oil on SB. The adsorption of oil in POME using ESB was better represented using Langmuir isotherm $(\mathrm{R} 2=0.992)$, indicating a monolayer adsorption of oil onto the ESB surface. In conclusion, ESB showed better potential for use as sorbent for removing emulsified oil from wastewater, particularly POME.
\end{abstract}

Keyword: Sago bark; Esterified sago bark; Sago fibre; Palm oil mill effluent; Oil removal 